\title{
Association of alpha-thalassemia, TNF-alpha (-308G>A) and VCAM-1 (c.1238G>C) gene polymorphisms with cerebrovascular disease in a newborn cohort of 411 children with sickle cell anemia
}

\author{
André Rolim Belisário a,b,*, Frederico Lisboa Nogueira ${ }^{\mathrm{b}}$, Rahyssa Sales Rodrigues ${ }^{\mathrm{c}}$, Nayara Evelin Toledo ${ }^{\mathrm{c}}$, \\ Ana Luiza Moreira Cattabriga ${ }^{c}$, Cibele Velloso-Rodrigues ${ }^{\mathrm{d}}$, Filipe Otávio Chaves Duarte ${ }^{\mathrm{b}}$, \\ Célia Maria Silva ${ }^{\mathrm{b}, \mathrm{c}}$, Marcos Borato Viana ${ }^{\mathrm{b}}$ \\ a Centro de Tecidos Biológicos de Minas Gerais, Fundação Hemominas, Lagoa Santa, Minas Gerais, Brazil \\ b Faculdade de Medicina/NUPAD, Universidade Federal de Minas Gerais (UFMG), Belo Horizonte, Minas Gerais, Brazil \\ c Serviço de Pesquisa, Fundação Hemominas, Belo Horizonte, Minas Gerais, Brazil \\ d Departmento Básico - Área de Saúde, Universidade Federal de Juiz de Fora (UFJF), Juiz de Fora, Minas Gerais, Brazil
}

\section{A R T I C L E I N F O}

\section{Article history:}

Submitted 13 May 2014

Revised 2 August 2014

Accepted 2 August 2014

Available online 27 August 2014

(Communicated by M. Narla, DSc, 02 August 2014)

Keywords:

Sickle cell anemia

Stroke

VCAM-1

TNF-alpha

Alpha-thalassemia

\begin{abstract}
A B S T R A C T
Cerebrovascular disease (CVD) is a severe complication associated with sickle cell anemia. Abnormal transcranial Doppler (TCD) identifies some children at high risk, but other markers would be helpful. This cohort study was aimed at evaluating the effects of genetic biomarkers on the risk of developing CVD in children from Minas Gerais, Brazil. Clinical and hematological data were retrieved from children's records. Outcomes studied were overt ischemic stroke and CVD (overt ischemic stroke, transient ischemic attack, abnormal TCD, or abnormal cerebral angiography). Out of 411 children, $386(93.9 \%)$ had SS genotype, $23(5.6 \%)$ had $S \beta^{0}$-thal and two had severe $S \beta^{+}$-thal $(0.5 \%)$. Frequency of CVD was lower in S $\beta$-thal group $(p=0.05)$. No effect of VCAM-1 polymorphism on stroke or CVD risks was detected. Cumulative incidence of stroke was significantly higher for children with TNF- $\alpha$ A allele $(p=0.02)$ and lower for children with HBA deletion $(p=0.02)$. However, no association between CVD and TNF- $\alpha-308 \mathrm{G}>\mathrm{A}$ was found. CVD cumulative incidence was significantly lower for children with HBA deletion $(p=0.004)$. This study found no association between VCAM1 c.1238G $>C$ and stroke. An association between stroke and TNF- $\alpha-308$ A allele has been suggested. Our results have confirmed the protective role of $H B A$ deletion against stroke and CVD.
\end{abstract}

(C) 2014 Elsevier Inc. All rights reserved.

\section{Introduction}

Sickle cell anemia (SCA) is a monogenic disorder caused by a homozygous mutation in the $\beta$-globin gene (HBB:c.20A $>$ T, p.E6V), resulting in early death and morbidity [1]. Cerebrovascular complications are very common in patients suffering from SCA. Cerebrovascular disease (CVD) includes overt stroke, silent infarcts, transient ischemic attack (TIA), abnormal magnetic resonance angiography (MRA), and abnormal transcranial Doppler (TCD). Overt stroke is the most catastrophic of them and occurs in $11 \%$ of patients by the age of twenty [2]. CVD affects almost one-half of SCA patients by the age of fourteen [3].

\footnotetext{
* Corresponding author at: Biological Tissue Center, Hemominas Foundation, Rua das Goiabeiras, nº 779, Lagoa Santa, Zip Code 33400-000, Brazil. Fax: +55 3132489579.

E-mail addresses: andrebelisario@yahoo.com.br (A.R. Belisário),

fredericoln@gmail.com (F.L. Nogueira), rahyssa_rodrigues@yahoo.com.br (R.S. Rodrigues), nayara_005@yahoo.com.br (N.E. Toledo), analuizacattabriga@hotmail.com (A.L.M. Cattabriga), cvbiogenet@yahoo.com.br (C. Velloso-Rodrigues), focduarte@gmail.com (F.O.C. Duarte), celia.cmaria@gmail.com (C.M. Silva), vianamb@gmail.com (M.B. Viana).
}

Currently, TCD ultrasonography is the only clinical useful prognostic tool available to detect increased risk of stroke in children with SCA. Prophylactic chronic erythrocyte transfusion therapy reduces in $92 \%$ the risk of occurrence of stroke in SCA patients at high risk [4]. The TCD test is very sensitive but only moderately specific because $60 \%$ of untreated children at high risk of experiencing stroke, as indicated by TCD, did not experience any episode of stroke [5]; therefore, it would have been harmful for these subjects to be exposed to the side effects of chronic transfusion therapy. It has been estimated that to prevent the occurrence of one stroke, seven children would receive chronic transfusion therapy [6]. Moreover, there are other limitations associated with TCD screening: stroke can occur in patients showing normal TCD results [5,7]; there can be relatively large intra-subject variability [8]; access to TCD and chronic transfusion therapy may be limited $[9,10]$, especially in developing countries [10]; adherence to screening programs can be a crucial problem [11,12]; family members and physicians may be reluctant to accept chronic transfusion therapy. Because of these shortcomings, it is necessary to identify biomarkers that can assess the risk of developing stroke with high specificity. 
Results obtained using several genetic biomarkers have been reported in literature. However, some of these results are controversial and therefore require adequate validation [13]. For instance, literature reports indicated that homozygous polymorphic -308G allele (c.-488G; rs1800629) in the promoter region of tumor necrosis factor alpha (TNF- $\alpha$ ) gene is associated with an increased risk of stroke [14,15]; whereas, another study reported no such association [16]. Previously, $\alpha$-globin gene (HBA) deletion has confirmed a protective effect against stroke and CVD [2,3,16-20], but findings from two recent studies indicated no such association [21,22]. Previous evidence has demonstrated that the vascular cell adhesion molecule 1 (VCAM-1) gene coding single-nucleotide polymorphism (SNP) c.1238G >C (rs3783613) may be protective against stroke in SCA [23]. However, no further research was done to confirm this finding. The present study evaluated the influences of TNF- $\alpha-308 \mathrm{G}>\mathrm{A}$ and VCAM1 c. $1238 \mathrm{G}>$ C polymorphisms, $H B A$ deletion status, and sickle cell genotype on the risk of developing CVD in the Minas Gerais state SCA newborn cohort, Brazil.

\section{Material and methods}

\section{Study design}

This is a retrospective cohort study involving children with SCA. Between January 1999 and December 2008, the Newborn Screening Program diagnosed 1066 children with HbFS profile in the state of Minas Gerais located at the southeastern part of Brazil. Out of 1066 children, 554 children were scheduled to have their first clinical appointment in the outpatient care unit of Hemominas Foundation, which is situated in the state capital Belo Horizonte. Among these 554 children, 49 children died before the study began (March 2011); 32 children were transferred to another outpatient care unit, and one child was subjected to private practice follow-up. The remaining 472 children were eligible for participation. Enrollment was closed in July 2013. Out of these 472 children, parents of five children did not allow their children to participate in this study, four children were transferred to another outpatient care unit after the beginning of the study, four children died during the study, and 38 children could not be reached for blood collection during the study program. Eight children with a double heterozygous mutation for $\mathrm{HbS}$ and hereditary persistence of fetal hemoglobin (HPFH) and two children who were proven to be $\mathrm{S} \beta^{+}$-thalassemia $\left(\mathrm{S} \beta^{+}\right.$-thal) positive and who had a steady state relative concentration of $\mathrm{HbA}$ above $7 \%$ were also excluded from this study. Therefore, the study population consisted of 411 children with genotypes $\mathrm{SS}, \mathrm{S} \beta^{0}$-thalassemia $\left(\mathrm{S}^{0}\right.$-thal) or $\mathrm{S} \beta^{+}$-thal type I (less than $7 \%$ of $\mathrm{HbA}$; clinical and hematological features similar to $\mathrm{SB}^{0}$-thal [24]). In a previous study, the prevalence of the Central African Republic, Benin, Arab-Indian and atypical $\beta^{\mathrm{S}}$ haplotype alleles in 208 of these children (only those with homozygous $\beta^{S}$ allele) was $0.57,0.42,0.005$, and 0.01 , respectively. No association between $\beta^{S}$ haplotypes and CVD was detected [25].

The study protocol was approved by the Institutional Review Board. Written informed consent was obtained from parents or guardian of every child in accordance with the rule set up by the "Declaration of Helsinki" guidelines and children's assent was obtained, when appropriate.

\section{Molecular analysis}

Genomic DNA extraction from blood samples was carried out by using a commercial kit (QIA amp, DNA Blood Mini Kit; Qiagen; Hilden, Germany). VCAM-1 c.1238G >C ( $r$ 3783613) and TNF- $\alpha-308 \mathrm{G}>\mathrm{A}$ (c.488G $>$ A; rs 1800629) polymorphisms were determined by PCR/RFLP as described previously $[23,26]$. Furthermore, at least $5 \%$ of the samples were randomly selected for DNA sequencing to confirm the reproducibility of PCR/RFLP results. DNA sequencing was done in ABI Prism
3130 Analyzer (Applied Biosystems; Foster City, CA, USA). Presence of $\beta^{S}$ allele was confirmed by PCR/RFLP analysis as described previously [25]. Heterozygous children for $\beta^{S}$ allele had $H B B$ sequenced to confirm the presence of $S \beta^{0}$-thal or $S \beta^{+}$-thal genotype. Molecular analyses were performed on children with steady state $\mathrm{HbF}$ concentration equal or greater than $30 \%$, suggesting HbS/HPFH genotype [27]. HPFH 1, 2 and 3 deletions were detected by gap-PCR as described previously [28]. Detection of $H B A$ more frequent deletions $\left(-\alpha^{3.7},-\alpha^{4.2},-{ }_{\mathrm{SEA}},-{ }^{\mathrm{FIL}}\right.$, $-{ }^{\mathrm{MED}},-(\alpha)^{20.5}$, and $-{ }^{\mathrm{THAI}}$ ) was carried out by multiplex gap PCR as described previously [29]; the primers' annealing temperature was increased to $62{ }^{\circ} \mathrm{C}$. For further confirmation, $20 \%$ of the samples were retested for $H B A$ deletions to validate the results.

\section{Clinical and hematological data}

Clinical and hematological information regarding participants' phenotypes were extracted from medical records and entered into a specific database.

TCD velocities were obtained as part of the standard care procedure. TCD examinations were performed and analyzed by an individual expert (C.M.S.). The STOP study protocol [4] has been used since 2007, with pulse TCD and a $2 \mathrm{MHz}$ probe for a full Doppler test (model EME TC 2000, Nicolet; Madison, WI, USA). Following a standard care procedure, MRA was recommended to children with inadequate TCD, children with basilar arterial velocity above $130 \mathrm{~cm} / \mathrm{s}$, and children with anterior cerebral arterial (ACA) velocity above $170 \mathrm{~cm} / \mathrm{s}$.

Overt ischemic stroke, which was defined as a neurological deficit lasting more than $24 \mathrm{~h}$, was diagnosed by a hematologist who was in charge of the follow-up study, and the diagnosis was done on the basis of available clinical and imaging results. Intracranial hemorrhage was not considered in the category of overt stroke. TIA was defined by the display of neurological signs following vascular disruption that resolve within $24 \mathrm{~h}$ [2]. Abnormal MRA was defined as stenosis or apparent occlusion of any vessel or arterial tortuosity, and Moyamoya disease [30]. Cerebrovascular disease (CVD) was defined in the present study by the occurrence of at least one of the following clinical events: overt ischemic stroke; abnormal TCD as originally defined by STOP investigators (the highest time-averaged mean blood-flow velocity [TAMMX] $\geq 200 \mathrm{~cm} / \mathrm{s}$ in the middle cerebral artery [MCA] and the internal carotid artery [ICA]) [4]; two consecutive TCD exams revealing the TAMMX equal or above $170 \mathrm{~cm} / \mathrm{s}$ in the anterior cerebral arteries [31]; abnormal MRA; and history of TIA. Because some subjects had experienced multiple cerebrovascular events, the first experience was used for dating the occurrence of the event. For subjects who had multiple TCD exams, the last exam was considered for the definition and dating. For children undergoing chronic transfusion therapy, treatment with hydroxyurea, or bone marrow transplantation, results from the last TCD exam before the initiation of therapy were considered.

White blood cell (WBC) count was determined using electronic cell counter (T-890, COULTER; Hialeah). Percentage of HbF was quantified by radial immunodiffusion (HbF Quiplate; Helena Laboratories; Beaumont). Arithmetic mean of WBC count and HbF concentration was calculated for children after they crossed the age of two years and a steady state value was obtained from these calculations. Values obtained from tests performed after blood transfusion (up to 90 days) and during significant clinical illness (serious infection, acute splenic sequestration, aplastic crisis) were disregarded. For children undergoing chronic transfusion therapy, treatment with hydroxyurea, or bone marrow transplantation, steady state values were determined from the mean of values registered before the initiation of therapy.

\section{Statistical analysis}

Continuous variables were expressed as mean \pm standard deviation and nominal variables as percentages. The Kolmogorov-Smirnov 
goodness-fit test was used to evaluate the normal distribution of continuous variables. For continuous variables that were normally distributed, the unpaired $t$-test was used to compare different groups. The nonparametric Mann-Whitney $U$ test was used for continuous variables that were not normally distributed. Two outcomes were studied in the present report: 1) Overt ischemic stroke; and 2) CVD. Except in the overall analyses or when considering sickle cell genotypes, $\mathrm{S} \beta^{0}$-thal and $\mathrm{S}^{+}$-thal type I children were not included in the statistical analysis of outcomes because they have less probability to have a stroke event [2] or CVD (see Results). Univariate associations between outcomes and covariates (genetic risk factors) were evaluated using two-tailed chi-square or Fisher's exact test. Statistically significant values were set at $p \leq 0.05$. Cumulative incidences of overt stroke or CVD were estimated by using a Kaplan-Meier method [function ( 1 - survival)] and the log rank test was used to compare different subgroups. Birth date determined entry into the study program. Beginning of chronic transfusion therapy, hydroxyurea treatment, bone marrow transplantation, death by causes unrelated to outcomes, and last clinical visit (last TCD or MRA test for CDV) without events until July 2013 (end of study) were reasons for censored observations. Cox's regression was used to determine the independent effect of each genetic risk factor. The initial multivariate model included all covariates potentially associated with outcomes. The covariates were removed from the model, one by one through stepwise analysis and the final model included only those covariates that were statistically significant at $p<0.10$. Statistical analyses were performed with SPSS 17.0 software (SPSS Inc.; Chicago, IL, USA).

\section{Results}

\section{Characteristics of subjects}

Out of 411 children enrolled in this study, 386 (93.9\%) had HbSS genotype, $23(5.6 \%)$ had $S \beta^{0}$-thal and two $(0.5 \%)$ had $S \beta^{+}$-thal type I genotype. Children had a mean age of $9.56 \pm 2.95$ years (range 4.5-14.5 years), and 208 (50.6\%) of them were male. Clinical, hematological, and genetic characteristics of the participants are shown in Table 1. No children with $S \beta^{0}$-thal $/ S \beta^{+}$-thal had overt stroke or CVD. Frequency of CVD was significantly lower in children with $\mathrm{S} \beta^{0}$-thal $/ \mathrm{S} \beta^{+}$-thal $(0 /$ $20)$ than in SS children $(61 / 348 ; p=0.05)$. Age and steady state WBC count were significantly lower for $\mathrm{S} \beta^{0}$-thal $/ \mathrm{S} \beta^{+}$-thal group in comparison to the SS group ( $p=0.05$ and 0.04 , respectively). No other difference was found between $\mathrm{SS}$ and $\mathrm{S} \beta^{0}$-thal/S$\beta^{+}$-thal groups (Table 1 ). Mean followup was $7.67 \pm 2.95$ years (range 2.01-14.14 years), which correspond to 3152 patient-years. The overall prevalence of overt stroke was 5.1\% (95\% CI 3.0\%-7.2\%) and the cumulative incidence of overt stroke by the age of 8.5 years was $6.6 \%$ ( $95 \%$ CI $3.9 \%-9.3 \%$; Fig. $1 \mathrm{~A})$. The overall prevalence of CVD was $16.6 \%$ (95\% CI 13.0\%-20.6\%) and the cumulative incidence of CVD by the age of 11.5 years was $32.7 \%$ (95\% CI 22.7\%-42.7\%; Fig. 1B).

\section{Genotyping results}

Analysis of $H B A$ deletions showed that 299 children (72.7\%) were $\alpha \alpha / \alpha \alpha, 105$ (25.5\%) $\alpha \alpha /-\alpha^{3.7}$ and seven (1.7\%) $-\alpha^{3.7} /-\alpha^{3.7}$. This

Table 1

Clinical, hematological and genetic characteristics of children with sickle cell disease in Minas Gerais, Brazil.

\begin{tabular}{|c|c|c|c|c|c|c|}
\hline \multirow[t]{2}{*}{ Variables } & \multicolumn{2}{|l|}{ Genotype } & \multirow{2}{*}{$\begin{array}{l}\text { Total } \\
\mathrm{n}=411\end{array}$} & \multirow[t]{2}{*}{$p$ value } & \multirow[t]{2}{*}{ Odds ratio } & \multirow[t]{2}{*}{$95 \% \mathrm{CI}$} \\
\hline & $\begin{array}{l}\mathrm{SS} \\
\mathrm{n}=386\end{array}$ & $\begin{array}{l}\mathrm{S} \beta^{0} \text {-thal } / \mathrm{S} \beta^{+} \text {-thal } \\
\mathrm{n}=25\end{array}$ & & & & \\
\hline \multicolumn{7}{|l|}{ Gender } \\
\hline Male & $196(50.8 \%)$ & $12(48 \%)$ & $208(50.6 \%)$ & $0.78^{\mathrm{a}}$ & 1.11 & $0.49-2.51$ \\
\hline Female & $190(48.9 \%)$ & $13(52 \%)$ & $203(49.4 \%)$ & & & \\
\hline Age (years) & $9.63 \pm 2.99$ & $8.52 \pm 2.03$ & $9.56 \pm 2.95$ & $0.05^{\mathrm{b}}$ & & \\
\hline \multicolumn{7}{|l|}{ Outcome } \\
\hline Overt stroke & $21(5.4 \%)$ & $0(0 \%)$ & $21(5.1 \%)$ & $0.63^{\mathrm{c}}$ & 0.94 & $0.91-0.96$ \\
\hline Cerebrovascular disease $^{\mathrm{d}}$ & $61 / 348(17.5 \%)$ & $0 / 20(0 \%)$ & $61 / 368(16.6 \%)$ & $0.05^{\mathrm{c}}$ & 0.93 & $0.90-0.96$ \\
\hline Overt stroke & $19(5.5 \%)$ & $0(0 \%)$ & $19(5.2 \%)$ & & & \\
\hline High risk TCD & $29(8.3 \%)$ & $0(0 \%)$ & $29(7.9 \%)$ & & & \\
\hline TAMMX $>170 \mathrm{~cm} / \mathrm{s}$ in ACA & $2(0.6 \%)$ & $0(0 \%)$ & $2(0.5 \%)$ & & & \\
\hline Transient ischemic attack & $7(2 \%)$ & $0(0 \%)$ & $7(1.9 \%)$ & & & \\
\hline Abnormal MRA & $4(1.1 \%)$ & $0(0 \%)$ & $4(1.1 \%)$ & & & \\
\hline \multicolumn{7}{|l|}{ Hematologic variables } \\
\hline WBC $\left(10^{9} / \mathrm{L} ; \mathrm{n}=203\right)$ & $16.13 \pm 3.36$ & $13.86 \pm 3.1$ & $16.03 \pm 3.37$ & $0.048^{e}$ & & \\
\hline $\mathrm{Hb} \mathrm{F}(\% ; \mathrm{n}=194)$ & $16.25 \pm 7.34$ & $19.59 \pm 8.15$ & $16.41 \pm 4.38$ & $0.19^{\mathrm{e}}$ & & \\
\hline \multicolumn{7}{|l|}{ Genetic status } \\
\hline \multicolumn{7}{|l|}{ VCAM1 c. $1238 \mathrm{G}>\mathrm{C}$} \\
\hline GG & $333(86.3 \%)$ & $23(92 \%)$ & $356(86,6 \%)$ & $0.55^{\mathrm{c}}$ & 0.55 & $0.13-2.38$ \\
\hline GC & $53(13.7 \%)$ & $2(8 \%)$ & $55(13.4 \%)$ & & & \\
\hline $\mathrm{CC}$ & $0(0 \%)$ & $0(0 \%)$ & $0(0 \%)$ & & & \\
\hline \multicolumn{7}{|l|}{ TNF- $\alpha-308 G>A$} \\
\hline GG & $283(73.3 \%)$ & $16(64 \%)$ & $299(72.7 \%)$ & $0.35^{\mathrm{c}, \mathrm{f}}$ & 1.54 & $0.66-3.6$ \\
\hline GA & $97(25.1 \%)$ & $9(36 \%)$ & $106(25,8 \%)$ & & & \\
\hline $\mathrm{AA}$ & $6(1.6 \%)$ & $0(0 \%)$ & $6(1.5 \%)$ & & & \\
\hline \multicolumn{7}{|l|}{ HBA deletion status } \\
\hline$\alpha \alpha / \alpha \alpha$ & $281(72.8 \%)$ & $18(72 \%)$ & $299(72.7 \%)$ & $1.00^{\mathrm{c}, \mathrm{g}}$ & 1.04 & $0.42-2.56$ \\
\hline$\alpha \alpha /-\alpha^{3.7}$ & $98(25.4 \%)$ & $7(28 \%)$ & $105(25.5 \%)$ & & & \\
\hline$-\alpha^{3.7} /-\alpha^{3.7}$ & $7(1.8 \%)$ & $0(0 \%)$ & $7(1.7 \%)$ & & & \\
\hline \multicolumn{7}{|l|}{$\mathrm{X}^{2}$} \\
\hline \multicolumn{7}{|l|}{ b Mann-Whitney test. } \\
\hline \multicolumn{7}{|c|}{ c Fisher's exact test. } \\
\hline \multirow{2}{*}{\multicolumn{7}{|c|}{$\begin{array}{l}\text { d } 43 \text { children did not have any of the clinical neurologic events, but had no valid TCD or MRA data to be classified as having or not having a cerebrovascular disease. } \\
\text { e Unpaired } t \text {-test. }\end{array}$}} \\
\hline & & & & & & \\
\hline \multicolumn{7}{|c|}{ f GG versus GA/AA. } \\
\hline g $\alpha \alpha / \alpha \alpha$ versus $\alpha \alpha /-\alpha^{3.7}$ or - & & & & & & \\
\hline
\end{tabular}



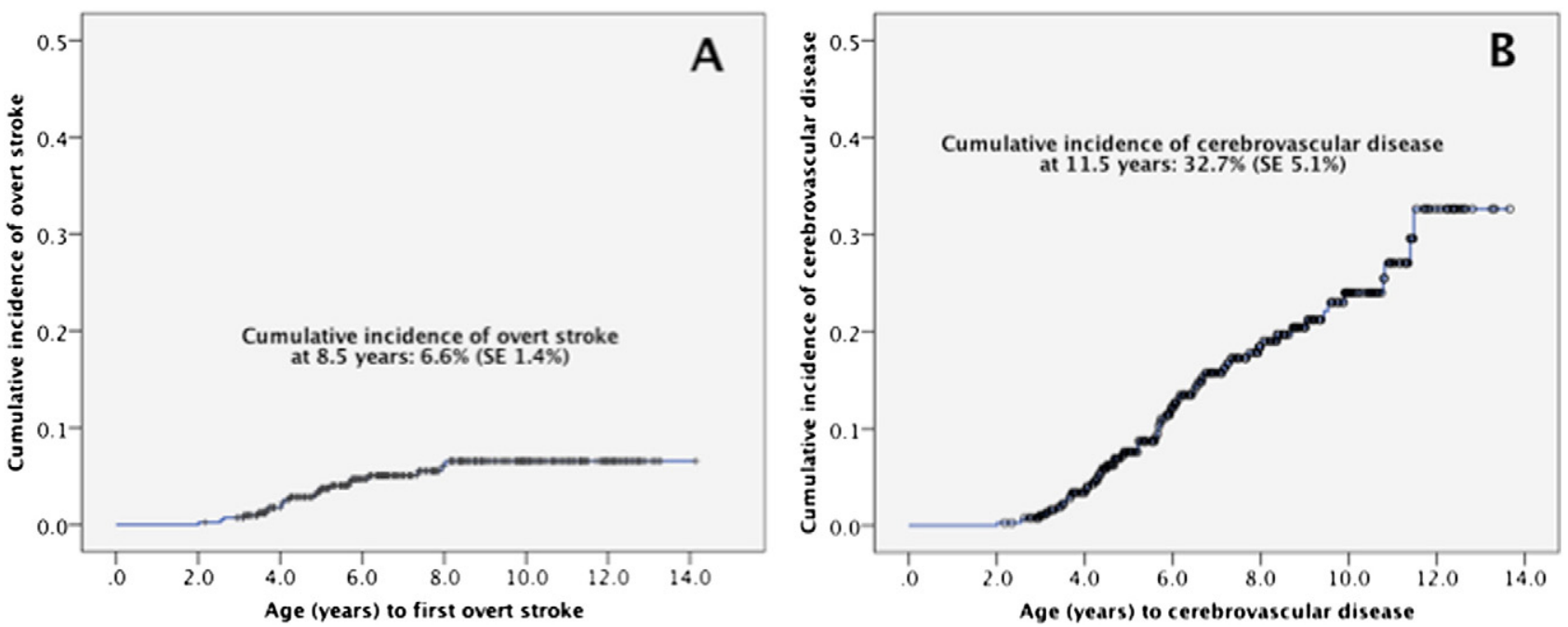

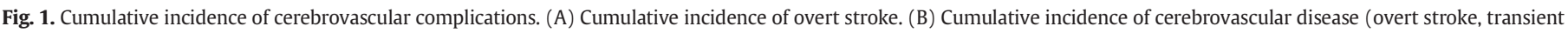
ischemic attack, abnormal TCD, or abnormal cerebral angiography). Function: ( 1 - survival), according to the Kaplan-Meier method.

means only $-\alpha^{3.7}$ deletion was detected. As far as TNF- $\alpha$ gene polymorphism (-308G>A) was concerned, 299 (72.7\%) children had GG, $106(25.8 \%)$ had GA, and six (1.5\%) had AA genotypes. For VCAM1 gene polymorphism (c.1238G>C), 356 (86.6\%) children had GG genotype and 55 (13.4\%) had GC (Table 1$)$.

Among children with $\mathrm{SB}^{0}$-thal $(\mathrm{n}=23), 10$ children $(43.5 \%)$ had the nonsense codon $39(\mathrm{C}>\mathrm{T})$ mutation, nine had (39.1\%) IVS-I-1 (G>A) mutation, three had (13\%) IVS-II-1 ( $\mathrm{G}>\mathrm{A})$ mutation, and one child had (4.4\%) IVS-I-2 ( $>C$ C) mutation. One child with $S \beta^{+}$-thal type I had the mutation IVS-1-110 (G>A) and the other one had the IVS-I-5 (G>A). Six (75\%) children with S/HPFH genotype had the deletion type 2 and two (25\%), had type 1 .

\section{Genetic risk factors for overt stroke in children with HbSS genotype}

The prevalence of overt stroke was 3.9\% (11/283) for children who had TNF- $\alpha$ GG genotype. It was 9.7\% (10/103) for those with GA or AA genotypes. The cumulative incidence of overt stroke was significantly higher for children with TNF- $\alpha$ GA or AA genotypes compared to children with GG genotype ( $p=0.02$; Fig. $2 \mathrm{~A}$ ). The prevalence of overt

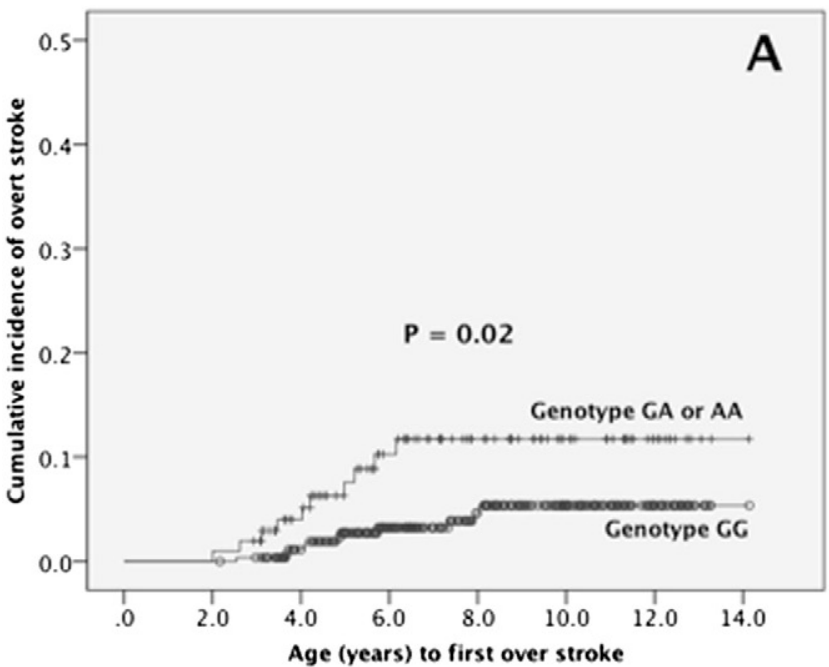

stroke was 7.1\% (20/281) for children without HBA deletion $(\alpha \alpha / \alpha \alpha)$. It was $1 \%(1 / 105)$ for those with one or two $-\alpha^{3.7}$ deletions. The cumulative incidence of overt stroke was significantly lower for children with HBA deletion compared to no deletions ( $p=0.02$; Fig. 2B). The cumulative incidences of overt stroke for VCAM1 GG and GC genotype groups were not significantly different $(p=0.49)$. The final multivariate model for predicting risk of overt stroke incidence included TNF- $\alpha$ $308 \mathrm{G}>\mathrm{A}$ polymorphism and $H B A$ deletion status. The relative risk of overt stroke for children with $\alpha \alpha / \alpha \alpha$ genotype was about 7 times higher (95\% CI 0.97-53.9) than for those with $-\alpha^{3.7}$ deletions. It was 2.5 times higher for children with GA or AA than for those with GG at TNF- $\alpha-308 G>A$ polymorphic site (95\% CI 1.07-5.91; Table 2).

\section{Genetic risk factors for CVD in children with HbSS genotype}

The prevalence of CVD was $17.5 \%$ (45/257) for children who had TNF- $\alpha$ GG genotype. It was $17.6 \%$ (16/91) for those with GA or AA genotypes. Accordingly, the cumulative incidences of CVD were similar for both groups $(p=0.7)$. The prevalence of CVD for children with the VCAM1 GG genotype was $17.3 \%$ (52/301). It was $19.1 \%(9 / 47)$ for

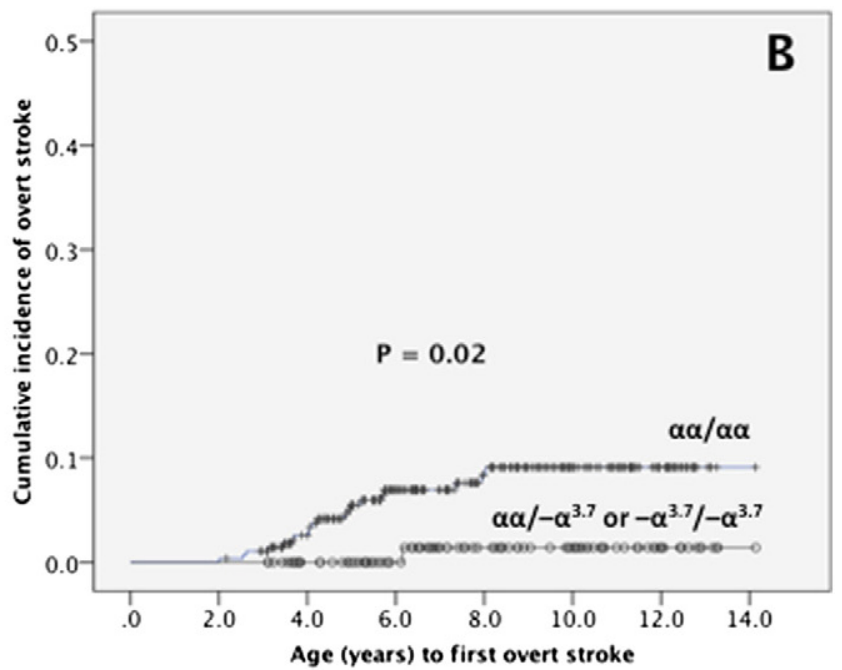

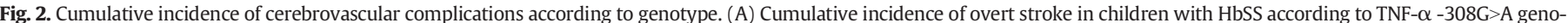

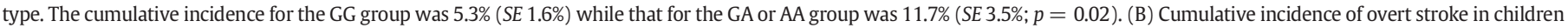

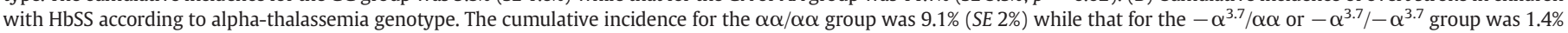
(SE 1.4\%; $p=0.02$; only one $-\alpha^{3.7} / \alpha \alpha$ child had a stroke). Function: ( 1 - survival), according to the Kaplan-Meier method. 
Table 2

Multivariate Cox's regression analyses to predict overt stroke in children with sickle cell anemia in Minas Gerais, Brazil.

\begin{tabular}{|c|c|c|c|}
\hline Variables & Relative risk & 95\% confidence interval & $p$ value \\
\hline \multicolumn{4}{|l|}{ Model 1: All covariates } \\
\hline VCAM1 c.1238G>C genotype & $1.67^{\mathrm{a}}$ & $0.56-4.96$ & 0.35 \\
\hline TNF- $\alpha-308 \mathrm{G}>$ A genotype & $2.52^{\mathrm{b}}$ & $1.07-5.93$ & 0.03 \\
\hline HBA deletion status & $7.47^{c}$ & $1.0-55.86$ & 0.05 \\
\hline \multicolumn{4}{|c|}{ Final model: Only covariates with $p<0.1$} \\
\hline TNF- $\alpha$ G308A genotype & $2.5^{\mathrm{b}}$ & $1.07-5.91$ & 0.03 \\
\hline HBA deletion status & $7.23^{\mathrm{c}}$ & $0.97-53.95$ & 0.05 \\
\hline
\end{tabular}

a GG to GC relative risk for overt stroke.

b GA or AA to GG relative risk for overt stroke.

c $\alpha \alpha / \alpha \alpha$ to $\alpha \alpha /-\alpha^{3.7}$ or $-\alpha^{3.7} /-\alpha^{3.7}$ relative risk for overt stroke.

those with the GC genotype. Corresponding cumulative incidences of CVD were not significantly different $(p=0.73)$. The prevalence of CVD was $21.3 \%$ (54/253) for children without HBA deletion $(\alpha \alpha / \alpha \alpha)$. It was $7.4 \%$ (7/95) for those with one or two $-\alpha^{3.7}$ deletions. The cumulative incidence of CVD was significantly lower for children with one or two HBA deletions ( $p=0.004$; Fig. 3 ). The final multivariate model for predicting the risk of developing CVD included the HBA deletion status only. The risk of developing CVD in children with one or two $-\alpha^{3.7}$ hybrid genes was 3 times lower than those with no HBA deletions (95\% CI: 1.4-6.6) (Table 3).

\section{Discussion}

We have studied the effect of genetic risk factors that have previously been associated with stroke in children with SCA. Our results suggested no association between VCAM1 c.1238G $>$ C polymorphism and overt stroke or CVD. Previously published results suggested the association of minor allele $C$ with a lower risk of stroke [23]. Nonsynonymous c.1238G >C SNP leads to a conservative amino acid change (Gly>Ala) at the 413th position in the immunoglobulin domain 5 of VCAM1 molecule. This molecule has a large surface of interaction with the corresponding receptor, and thus, the weakly interacting methyl group added by substitution of glycine with alanine would not interfere with the proper function of the protein; therefore, the variant 413A may remain fully functional. Bioinformatic analyses using MutPred and PolyPhen2 algorithms also suggested that protein function would not be harmed, thereby providing support to our results

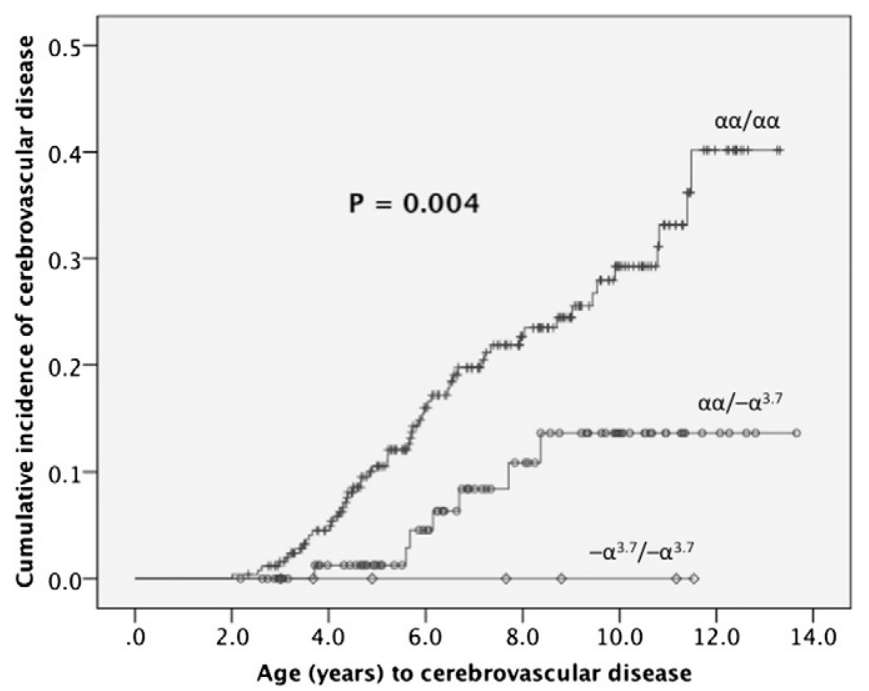

Fig. 3. Cumulative incidence of cerebrovascular disease in children with HbSS according to alpha-thalassemia genotype. The cumulative incidence for the $\alpha \alpha / \alpha \alpha$ group was $40.2 \%$ (SE 6.2\%) and that for the $-\alpha^{3.7} / \alpha \alpha$ group was $13.7 \%$ (SE 5.0\%); no child with the $-\alpha^{3.7} /-\alpha^{3.7}$ genotype had cerebrovascular disease (linear trend $p=0.004$ ). Function: (1 - survival), according to the Kaplan-Meier method.
Table 3

Multivariate Cox's regression analyses to predict cerebrovascular disease in children with sickle cell anemia in Minas Gerais, Brazil.

\begin{tabular}{|c|c|c|c|}
\hline Variables & Relative risk & 95\% confidence interval & $p$ value \\
\hline \multicolumn{4}{|l|}{ Model 1: All covariates } \\
\hline VCAM1 c.1238G>C genotype & $1.24^{\mathrm{a}}$ & $0.61-2.53$ & 0.55 \\
\hline TNF- $\alpha-308 \mathrm{G}>$ A genotype & $1.05^{\mathrm{b}}$ & $0.59-1.86$ & 0.87 \\
\hline HBA deletion status & $3.04^{c}$ & $1.38-6.69$ & 0.006 \\
\hline \multicolumn{4}{|c|}{ Final model: Only covariates with $p<0.1$} \\
\hline HBA deletion status & $3.00^{c}$ & $1.37-6.59$ & 0.006 \\
\hline
\end{tabular}

[32,33]. Furthermore, the 413A VCAM-1 variant showed neither any potential difference in protein isoform levels nor any impairment of in vitro cell-cell adhesion function [34].

This is the second study to assess the effect of VCAM1 c.1238G $>$ C polymorphism on the risk of stroke in children with SCA. Additional studies in different populations will be needed to confirm our findings.

The present study demonstrated that $-308 \mathrm{G}>\mathrm{A}$ polymorphism of the TNF- $\alpha$ gene was significantly associated with overt stroke, but not with CVD. Children with allele A had a 2.5-fold increased risk of getting overt stroke, thereby indicating a modest effect of this allele on susceptibility to overt stroke. Reports on TNF- $\alpha-308 \mathrm{G}>\mathrm{A}$ polymorphism and the risk of stroke in SCA subjects have been controversial. Some results showed an association of $G$ allele with higher risk of stroke [14,15], while other studies reported no such association [16,35]. Another study failed to find an association between TNF- $\alpha-308 \mathrm{G}>\mathrm{A}$ polymorphism and MRA/ MRI abnormalities in adults [36].

The present study is the first one to report an association between $-308 \mathrm{~A}$ allele and overt stroke. Subjects with sickle cell anemia have higher concentration of TNF- $\alpha$ than controls with HbAA $[37,38]$. The minor allele $A$ has been associated with higher rate of transcription of TNF- $\alpha$ gene [39], and higher cytokine levels in Brazilian children with SCA [40]. Based on current knowledge about pathophysiology of stroke in SCA [41], consequences secondary to high production of this pro-inflammatory cytokine such as stimulation of inflammation, activation of endothelial cells, activation of WBC [42], and induction of the coagulation cascade [43], would be consistent with an increased risk of stroke. TNF- $\alpha$ has been used to induce vaso-occlusion in sickle cell mice [44], adding further support to the biological plausibility of our findings. High levels of TNF- $\alpha$ have been associated with severe clinical manifestations in patients with SCA [38,45,46], and allele A was associated with higher risk of acquiring acute splenic sequestration [40]. Discrepancies in some previously published results may be due to differences in method design, outcome definition, and population variability. An intriguing observation derived from the present study was the lack of association between TNF- $\alpha-308 \mathrm{G}>\mathrm{A}$ SNP and CDV. This implies that allele A would produce some phenotypic modification that increases the risk of stroke, the last stage of CVD, but not the risk of previous stages, such as TCD abnormalities. It is possible that allele A plays a role in the end-stage vasculopathy in these children but it is difficult to understand pathophysiologically the lack of association between the SNP and CVA. This lack of association may indicate a true negative result and the association between TNF- $\alpha-308 \mathrm{G}>\mathrm{A}$ polymorphism and overt stroke may be regarded more probably as a false positive result. Further studies are needed to understand the real influence of TNF- $\alpha-308 \mathrm{G}>\mathrm{A}$ SNP on the risk of developing CVD.

As previously described by us and other researchers, HBA deletion was significantly associated with a decreased risk of overt stroke $[2,16,18,35,47]$ and CVD $[3,17,19,20,48]$. Children without $H B A$ deletion had a 7-fold increased risk of overt stroke and a 3-fold increased risk of CVD. Absence of this association found in recently published studies probably occurs due to lack of power to detect a difference [22], or due to a selection bias [21]. It is interesting to note that both cited 
reports showed a trend toward a protective association of $H B A$ deletion on CVD prevalence. In our experience, a high reticulocyte count was an independent risk factor for CVD in the multivariate analysis [49]. Reduction of reticulocyte count caused by HBA deletion [20] may be crucial to protect children from overt stroke and CVD. Prioritization of children without HBA deletions for scheduling TCD tests can be a potential useful tool for designing clinical protocols.

Our results showed that $\mathrm{S} \beta^{0}$-thal/severe $\mathrm{S} \beta^{+}$-thal genotypes were significantly associated with a decreased risk of CDV. Although no child with those genotypes had an overt stroke, the prevalence difference in SS children was not statistically significant probably because the number of $S \beta^{0}$-thal $/ S \beta^{+}$-thal cases and that of overt stroke events were both too small. A number of studies related to stroke risk factors have grouped together subjects with $\mathrm{SS}$ and $\mathrm{S} \beta^{0}$-thal genotypes $[3,17,21,50]$. Although similar in other clinical aspects [51], the risk of stroke and CVD may be actually different as suggested by the present study and by other investigators [2]. As mentioned before for the HBA deletion status, sickle cell genotype is a potential marker to prioritize children for TCD and imaging exams, but prospective studies are needed to support TCD protocol recommendations based on genotypes.

One limitation of the present study was the use of medical files as the source of retrospective data, even though these records were generated for clinical follow-up and not for research. Although the final sample for this study $(n=411)$ represents $89.2 \%$ of the corresponding total population followed-up at Belo Horizonte Blood Center $(n=472), 38$ children could not be reached during the study period and may represent milder forms of sickle cell disease. Similarly, 43 children with no TCD or MRA testing may also represent a milder form of the disease. So the actual prevalence of CVD might have been overestimated in the present study and may have incorporated biasness in evaluating the genetic risk factors associated with CVD and stroke.

\section{Conclusions}

In summary, this cohort study was the first to contradict previously reported association between VCAM1 c.1238G $>$ C polymorphism and stroke in children with SCA. Furthermore, an association between TNF- $\alpha-308$ A allele and overt stroke, but not CVD, has been found. Also, our results have confirmed the protective role of the HBA deletion status against stroke and cerebrovascular disease. Our findings suggest that children with $S \beta^{0}$-thal/severe $S \beta^{+}$-thal genotype have a less risk of developing cerebrovascular disease than children with SS genotype. Because CVD is associated with significant morbidity in children with sickle cell disease, and since TCD screening has some recognized limitations in assigning risk for CVD, additional prospective studies are needed to refine CVD risk stratification in children with sickle cell disease.

\section{Acknowledgments}

The authors acknowledge all subjects and parents for their cooperation in the study. The authors also thank the financial support of HEMOMINAS, Newborn Screening Program (Nupad-UFMG), FAPEMIG (PPM-00266-13 (MBV)), CNPq (304530/2011-5 (MBV)), and CAPES.

\section{References}

[1] M.J. Stuart, R.L. Nagel, Sickle-cell disease, Lancet 364 (9442) (Oct 9-15 2004) 1343-1360 (PubMed PMID: 15474138).

[2] K. Ohene-Frempong, S.J. Weiner, L.A. Sleeper, S.T. Miller, S. Embury, J.W. Moohr, et al., Cerebrovascular accidents in sickle cell disease: rates and risk factors, Blood 91 (1) (Jan 1 1998) 288-294 (PubMed PMID: 9414296. Epub 1998/02/07. eng).

[3] F. Bernaudin, S. Verlhac, C. Arnaud, A. Kamdem, S. Chevret, I. Hau, et al., Impact of early transcranial Doppler screening and intensive therapy on cerebral vasculopathy outcome in a newborn sickle cell anemia cohort, Blood 117 (4) (Jan 27 2011) 1130-1140 (quiz 436. PubMed PMID: 21068435. Epub 2010/11/12. eng).

[4] R.J. Adams, V.C. McKie, L. Hsu, B. Files, E. Vichinsky, C. Pegelow, et al., Prevention of a first stroke by transfusions in children with sickle cell anemia and abnormal results on transcranial Doppler ultrasonography, N. Engl. J. Med. 339 (1) (Jul 2 1998) 5-11 (PubMed PMID: 9647873. Epub 1998/07/02. eng).
[5] R.J. Adams, V.C. McKie, E.M. Carl, F.T. Nichols, R. Perry, K. Brock, et al., Long-term stroke risk in children with sickle cell disease screened with transcranial Doppler, Ann. Neurol. 42 (5) (Nov 1997) 699-704 (PubMed PMID: 9392568. Epub 1997/ 12/10. eng.).

[6] L.C. Jordan, J.F. Casella, M.R. Debaun, Prospects for primary stroke prevention in children with sickle cell anaemia, Br. J. Haematol. 157 (1) (2012) 14-25.

[7] R.J. Adams, D.J. Brambilla, S. Granger, D. Gallagher, E. Vichinsky, M.R. Abboud, et al., Stroke and conversion to high risk in children screened with transcranial Doppler ultrasound during the STOP study, Blood 103 (10) (May 15 2004) 3689-3694 (PubMed PMID: 14751925).

[8] D.J. Brambilla, S.T. Miller, R.J. Adams, Intra-individual variation in blood flow velocities in cerebral arteries of children with sickle cell disease, Pediatr. Blood Cancer 49 (3) (Sep 2007) 318-322 (PubMed PMID: 17243135. Pubmed Central PMCID: 2867598. Epub 2007/01/24. eng.).

[9] D.C. Rees, M.C. Dick, S.E. Height, S. O'Driscoll, K.R. Pohl, D.E. Goss, et al., A simple index using age, hemoglobin, and aspartate transaminase predicts increased intracerebral blood velocity as measured by transcranial Doppler scanning in children with sickle cell anemia, Pediatrics 121 (6) (Jun 2008) e1628-e1632 (PubMed PMID: 18490379. Epub 2008/05/21. eng.).

[10] S.B. Ali, M. Moosang, L. King, J. Knight-Madden, M. Reid, Stroke recurrence in children with sickle cell disease treated with hydroxyurea following first clinical stroke, Am. J. Hematol. 86 (10) (Oct 2011) 846-850 (PubMed PMID: 21898530. Epub 2011/ 09/08. eng.).

[11] H.J. Fullerton, R.J. Adams, S. Zhao, S.C. Johnston, Declining stroke rates in Californian children with sickle cell disease, Blood 104 (2) (Jul 15 2004) 336-339 (PubMed PMID: 15054044. Epub 2004/04/01. eng.)

[12] M.J. Eckrich, W.C. Wang, E. Yang, P.G. Arbogast, A. Morrow, J.A. Dudley, et al., Adherence to transcranial Doppler screening guidelines among children with sickle cell disease, Pediatr. Blood Cancer 60 (2) (Feb 2013) 270-274 (PubMed PMID: 22744996).

[13] F. Menaa, Stroke in sickle cell anemia patients: a need for multidisciplinary approaches, Atherosclerosis 229 (2) (Aug 2013) 496-503 (PubMed PMID: 23746538).

[14] C. Hoppe, W. Klitz, K. D'Harlingue, S. Cheng, M. Grow, L. Steiner, et al., Confirmation of an association between the TNF(-308) promoter polymorphism and stroke risk in children with sickle cell anemia, Stroke 38 (8) (Aug 2007) 2241-2246 (PubMed PMID: 17600229. Epub 2007/06/30. eng.).

[15] C. Hoppe, W. Klitz, S. Cheng, R. Apple, L. Steiner, L. Robles, et al., Gene interactions and stroke risk in children with sickle cell anemia, Blood 103 (6) (Mar 15 2004) 2391-2396 (PubMed PMID: 14615367. Epub 2003/11/15. eng.).

[16] J.M. Flanagan, D.M. Frohlich, T.A. Howard, W.H. Schultz, C. Driscoll, R. Nagasubramanian, et al., Genetic predictors for stroke in children with sickle cell anemia, Blood 117 (24) (Jun 16 2011) 6681-6684 (Pubmed Central PMCID: 3123027. Epub 2011/04/26. eng.)

[17] L.L. Hsu, S.T. Miller, E. Wright, A. Kutlar, V. McKie, W. Wang, et al., Alpha thalassemia is associated with decreased risk of abnormal transcranial Doppler ultrasonography in children with sickle cell anemia, J. Pediatr. Hematol. Oncol. 25 (8) (Aug 2003) 622-628 (PubMed PMID: 12902915. Epub 2003/08/07. eng.).

[18] P. Sebastiani, M.F. Ramoni, V. Nolan, C.T. Baldwin, M.H. Steinberg, Genetic dissection and prognostic modeling of overt stroke in sickle cell anemia, Nat. Genet. 37 (4) (Apr 2005) 435-440 (PubMed PMID: 15778708. Pubmed Central PMCID: 2896308. Epub 2005/03/22. eng.).

[19] F. Bernaudin, S. Verlhac, S. Chevret, M. Torres, L. Coic, C. Arnaud, et al., G6PD deficiency, absence of alpha-thalassemia, and hemolytic rate at baseline are significant independent risk factors for abnormally high cerebral velocities in patients with sickle cell anemia, Blood 112 (10) (Nov 15 2008) 4314-4317 (PubMed PMID: 18772456. Epub 2008/09/06. eng.).

[20] A.R. Belisario C.V. Rodrigues, M.L. Martins, C.M. Silva, M.B. Viana, Coinheritance of alpha-thalassemia decreases the risk of cerebrovascular disease in a cohort of children with sickle cell anemia, Hemoglobin 34 (6) (2010) 516-529 (PubMed PMID: 21077759. Epub 2010/11/17. eng.).

[21] M. Thangarajh, G. Yang, D. Fuchs, M.R. Ponisio, R.C. McKinstry, A. Jaju, et al., Magnetic resonance angiography-defined intracranial vasculopathy is associated with silent cerebral infarcts and glucose-6-phosphate dehydrogenase mutation in children with sickle cell anaemia, Br. J. Haematol. 159 (3) (Nov 2012) 352-359 (PubMed PMID: 22958163)

[22] I.L. Filho, A.C. Leite, P.G. Moura, G.S. Ribeiro, A.C. Cavalcante, F.C. Azevedo, et al., Genetic polymorphisms and cerebrovascular disease in children with sickle cell anemia from Rio de Janeiro, Brazil, Arq. Neuropsiquiatr. 69 (3) (Jun 2011) 431-435 (PubMed PMID: 21755116. Epub 2011/07/15. eng.).

[23] JGt Taylor, D.C. Tang, S.A. Savage, S.F. Leitman, S.I. Heller, G.R. Serjeant, et al., Variants in the VCAM1 gene and risk for symptomatic stroke in sickle cell disease, Blood 100 (13) (Dec 15 2002) 4303-4309 (PubMed PMID: 12393616. Epub 2002/10/24. eng)

[24] G.R. Serjeant, B.E. Serjeant, R.A. Fraser, I.R. Hambleton, D.R. Higgs, A.E. Kulozik, et al., $\mathrm{Hb}$ S-beta-thalassemia: molecular, hematological and clinical comparisons, Hemoglobin 35 (1) (2011) 1-12 (PubMed PMID: 21250876).

[25] A.R. Belisario, M.L. Martins, A.M. Brito, C.V. Rodrigues, C.M. Silva, M.B. Viana, Betaglobin gene cluster haplotypes in a cohort of 221 children with sickle cell anemia or Sbeta-thalassemia and their association with clinical and hematological features, Acta Haematol. 124 (3) (2010) 162-170 (PubMed PMID: 20938172. Epub 2010/10/ 13. eng).

[26] V.J. Johnson, B. Yucesoy, M.I. Luster, Genotyping of single nucleotide polymorphisms in cytokine genes using real-time PCR allelic discrimination technology, Cytokine 27 (6) (Sep 21 2004) 135-141 (PubMed PMID: 15304242).

[27] D.A. Ngo, B. Aygun, I. Akinsheye, J.S. Hankins, I. Bhan, H.Y. Luo, et al., Fetal haemoglobin levels and haematological characteristics of compound heterozygotes 
for haemoglobin S and deletional hereditary persistence of fetal haemoglobin, $\mathrm{Br}$. J. Haematol. 156 (2) (2011) 259-264.

[28] J.E. Craig, R.A. Barnetson, J. Prior, J.L. Raven, S.L. Thein, Rapid detection of deletions causing delta beta thalassemia and hereditary persistence of fetal hemoglobin by enzymatic amplification, Blood 83 (6) (Mar 15 1994) 1673-1682 (PubMed PMID: 7510147).

[29] A.S. Tan, T.C. Quah, P.S. Low, S.S. Chong, A rapid and reliable 7-deletion multiplex polymerase chain reaction assay for alpha-thalassemia, Blood 98 (1) (Jul 12001 ) 250-251 (PubMed PMID: 11439976).

[30] R.G. Steen, T. Emudianughe, G.M. Hankins, L.W. Wynn, W.C. Wang, X. Xiong, et al., Brain imaging findings in pediatric patients with sickle cell disease, Radiology 228 (1) (Jul 2003) 216-225 (PubMed PMID: 12775848).

[31] J.L. Kwiatkowski, R. Zimmerman, B. Greenbaum, K. Ohene-Frempong, Stroke and elevated blood flow velocity in the anterior cerebral artery in sickle cell disease, J. Pediatr. Hematol. Oncol. 26 (5) (May 2004) 323-326 (PubMed PMID: 15111788. Epub 2004/04/28. eng.).

[32] B. Li, V.G. Krishnan, M.E. Mort, F. Xin, K.K. Kamati, D.N. Cooper, et al., Automated inference of molecular mechanisms of disease from amino acid substitutions, Bioinformatics 25 (21) (Nov 1 2009) 2744-2750 (PubMed PMID: 19734154. Pubmed Central PMCID: 3140805).

[33] I.A. Adzhubei, S. Schmidt, L. Peshkin, V.E. Ramensky, A. Gerasimova, P. Bork, et al., A method and server for predicting damaging missense mutations, Nat. Methods 7 (4) (Apr 2010) 248-249 (PubMed PMID: 20354512. Pubmed Central PMCID: 2855889).

[34] B. Schmitz, P. Vischer, E. Brand, K. Schmidt-Petersen, A. Korb-Pap, K. Guske, et al., Increased monocyte adhesion by endothelial expression of VCAM-1 missense variation in vitro, Atherosclerosis 230 (2) (Oct 2013) 185-190 (PubMed PMID: 24075742).

[35] I.F. Domingos, D.A. Falcao, B.L. Hatzlhofer, A.F. Cunha, M.N. Santos, D.M. Albuquerque, et al., Influence of the beta haplotype and alpha-thalassemia on stroke development in a Brazilian population with sickle cell anaemia, Ann. Hematol. 93 (7) (2014) 1123-1129.

[36] P. Vicari, G.S. Silva, M.A. Nogutti, F.M. Neto, N.J. dos Santos, A.R. Massaro, et al., Absence of association between TNF-alpha polymorphism and cerebral large-vessel abnormalities in adults with sickle cell anemia, Acta Haematol. 125 (3) (2011) 141-144 (PubMed PMID: 21160173. Epub 2010/12/17. eng.).

[37] A.S. Bowers, H.L. Reid, A. Greenidge, C. Landis, M. Reid, Blood viscosity and the expression of inflammatory and adhesion markers in homozygous sickle cell disease subjects with chronic leg ulcers, PLoS One 8 (7) (2013) e68929 (PubMed PMID: 23922670. Pubmed Central PMCID: 3724890).

[38] S. Kuvibidila, R. Gardner, D. Ode, L. Yu, G. Lane, R.P. Warrier, Tumor necrosis factor alpha in children with sickle cell disease in stable condition, J. Natl. Med. Assoc. 89 (9) (Sep 1997) 609-615 (PubMed PMID: 9302858. Pubmed Central PMCID: 2608260).

[39] K.M. Kroeger, K.S. Carville, L.J. Abraham, The - 308 tumor necrosis factor-alpha promoter polymorphism effects transcription, Mol. Immunol. 34 (5) (Apr 1997) 391-399 (PubMed PMID: 9293772).
[40] C. Cajado, B.A. Cerqueira, F.D. Couto, J.P. Moura-Neto, W. Vilas-Boas, M.J. Dorea, et al., TNF-alpha and IL-8: serum levels and gene polymorphisms $(-308 \mathrm{G}>\mathrm{A}$ and $-251 \mathrm{~A}>\mathrm{T}$ ) are associated with classical biomarkers and medical history in children with sickle cell anemia, Cytokine 56 (2) (Nov 2011) 312-317 (PubMed PMID: 21802960).

[41] P. Connes, S. Verlhac, F. Bernaudin, Advances in understanding the pathogenesis of cerebrovascular vasculopathy in sickle cell anaemia, Br. J. Haematol. 161 (4) (May 2013) 484-498 (PubMed PMID: 23496688).

[42] H.Z. Movat, Tumor necrosis factor and interleukin-1: role in acute inflammation and microvascular injury, J. Lab. Clin. Med. 110 (6) (Dec 1987) 668-681 (PubMed PMID: 3316455).

[43] K.A. Bauer, H. ten Cate, S. Barzegar, D.R. Spriggs, M.L. Sherman, R.D. Rosenberg, Tumor necrosis factor infusions have a procoagulant effect on the hemostatic mechanism of humans, Blood 74 (1) (Jul 1989) 165-172 (PubMed PMID: 2752108).

[44] A. Turhan, LA. Weiss, N. Mohandas, B.S. Coller, P.S. Frenette, Primary role for adherent leukocytes in sickle cell vascular occlusion: a new paradigm, Proc. Natl. Acad. Sci. U. S. A. 99 (5) (Mar 5 2002) 3047-3051 (PubMed PMID: 11880644. Pubmed Central PMCID: 122470).

[45] M.H. Qari, U. Dier, S.A. Mousa, Biomarkers of inflammation, growth factor, and coagulation activation in patients with sickle cell disease, Clin. Appl. Thromb. Hemost. 18 (2) (Mar-Apr 2012) 195-200 (PubMed PMID: 21949038).

[46] B. Keikhaei, A.R. Mohseni, R. Norouzirad, M. Alinejadi, S. Ghanbari, F. Shiravi, et al., Altered levels of pro-inflammatory cytokines in sickle cell disease patients during vaso-occlusive crises and the steady state condition, Eur. Cytokine Netw. 24 (1) (Mar 2013) 45-52 (PubMed PMID: 23608554).

[47] F.M. Gill, L.A. Sleeper, S.J. Weiner, A.K. Brown, R. Bellevue, R. Grover, et al., Clinical events in the first decade in a cohort of infants with sickle cell disease. Cooperative Study of Sickle Cell Disease, Blood 86 (2) (Jul 15 1995) 776-783 (PubMed PMID: 7606007. Epub 1995/07/15, eng.).

[48] S.E. Cox, J. Makani, D. Soka, V.S. L'Esperence, E. Kija, P. Dominguez-Salas, et al., Haptoglobin, alpha-thalassaemia and glucose-6-phosphate dehydrogenase polymorphisms and risk of abnormal transcranial Doppler among patients with sickle cell anaemia in Tanzania, Br. J. Haematol. 165 (5) (2014) 699-706.

[49] C.M. Silva, P. Giovani, M.B. Viana, High reticulocyte count is an independent risk factor for cerebrovascular disease in children with sickle cell anemia, Pediatr. Blood Cancer 56 (1) (Jan 2011) 116-121 (PubMed PMID: 20949593. Epub 2010/10/16. eng.).

[50] L. Chang Milbauer, P. Wei, J. Enenstein, A. Jiang, C.A. Hillery, J.P. Scott, et al., Genetic endothelial systems biology of sickle stroke risk, Blood 111 (7) (Apr 12008 ) 3872-3879 (PubMed PMID: 18156497. Pubmed Central PMCID: 2275038. Epub 2007/12/25. eng.).

[51] G.R. Serjeant, A.M. Sommereux, M. Stevenson, K. Mason, B.E. Serjeant, Comparison of sickle cell-beta0 thalassaemia with homozygous sickle cell disease, Br. J. Haematol. 41 (1) (Jan 1979) 83-93 (PubMed PMID: 420738). 